\title{
HeLa cell and buccal epithelial cell adhesion assays for detecting intestinal Escherichia coli with adhesive properties in ulcerative colitis
}

\author{
D A BURKE, A T R AXON \\ From the Gastroenterology Unit, The General Infirmary, Leeds
}

SUMMARY The two methods used to detect intestinal Escherichia coli in patients with ulcerative colitis, HeLa cell and buccal epithelial cell (BEC) adhesion assays, were compared. Both methods showed a significant difference between the adhesive property of colitic and control $E$ coli: $\mathrm{p}<0.0002$ and $\mathrm{p}<0.01$ for the buccal epithelial cell and HeLa cell methods, respectively. HeLa cells did not detect all BEC positive isolates which were quantitatively more adhesive than any control isolate. All BEC negative isolates were HeLa cell negative.

The BEC technique seems to be more sensitive for detecting adhesive $E$ coli in ulcerative colitis because the true incidence of adhesive $E$ coli in ulcerative colitis was higher than that determined by the HeLa cell method.

Escherichia coli with adhesive properties occur in $35 \%$ of patients with ulcerative colitis in relapse compared with $5 \%$ of normal controls, using the HeLa cell assay. ${ }^{1} \mathrm{HeLa}$ cells are a neoplastic tissue culture cell line originally derived from a carcinoma of the cervix and they bear little relationship to the cells of the gastrointestinal tract. The adhesive property of $E$ coli in patients with ulcerative colitis has also been studied using buccal epithelial cells (BEC) which have a closer association with the gastrointestinal tract; the technique is quantitative and simple to perform. ${ }^{2}$

The aim of this study was to compare the HeLa cell and BEC methods in the detection of adhesive $E$ coli using $E$ coli obtained from patients with ulcerative colitis and from controls.

\section{Material and methods}

$E$ coli were isolated from the stools of 25 patients with ulcerative colitis in relapse. Isolates from 13 patients and members of staff who had no evidence of intestinal inflammation were used as controls. $E$ coli isolates were stored on Dorset egg medium slopes in the dark and adhesion was assessed in both the HeLa cell and the BEC adhesion assays by two independent observers.

Accepted for publication 9 June 1987
HELA CELL ADHESION ASSAY

Adhesion to HeLa cells was performed using a modification of the methods described by Dickinson et al. ${ }^{1}$ HeLa cells (Flow Laboratories) were maintained in tissue culture in Eagle's minimal essential medium until confluent, they were then stripped and aliquotted using trypsin, transferred to plastic Petri dishes containing glass coverslips, and maintained in an atmosphere of $95 \%$ air and $5 \%$ carbon dioxide at $37^{\circ} \mathrm{C}$ until almost confluent. Incubation of the HeLa cells with the test bacteria differed from that described by Dickinson et al ${ }^{1}$ in that D-mannose was included in the incubation media to inhibit adhesion mediated by type 1 pili, and the bacterial concentration was increased to compare with that used in the BEC assay. Bacteria from an 18 hour nutrient agar slope culture grown at $37^{\circ} \mathrm{C}$ were suspended in minimal essential medium containing $1 \%$ D-mannose at a concentration of about $10^{8}$ bacterial cells $/ \mathrm{ml}$. After incubation for three hours at $37^{\circ} \mathrm{C}$ the glass coverslips were washed four times in phosphate buffered saline (pH 7.2), air dried, fixed in three parts methanol and one part acetic acid, and stained with dilute Giemsa at pH7. Assessment of adhesion by light microscopy was done according to Dickinson et al. ${ }^{1}$ Scattered bacteria or bacterial clumps unrelated to cell membranes were regarded as negative. A positive test was when bacteria were clearly seen to be adhering to more than $90 \%$ of the HeLa cells. As positive and 
negative controls two $E$ coli isolates from the previously described study ${ }^{1}$ were included in our assays.

BEC ADHESION ASSAY

The method was a modification of that described elsewhere ${ }^{2}$; BECs were obtained by gently scraping the buccal mucosa with a sterile spatula and suspending in phosphate buffered saline ( $\mathrm{pH} \mathrm{7 \cdot 2).} \mathrm{They}$ were then washed and harvested by centrifugation three times and resuspended at a concentration of about $10^{5}$ cells $/ \mathrm{ml}$ in phosphate buffered saline containing $1 \%$ D-mannose. BEC suspension $(0.5 \mathrm{ml})$ was added to $0.5 \mathrm{ml}$ of a washed suspension of the bacterial test strain at a concentration of about $10^{8}$ bacterial cells $/ \mathrm{ml}$ obtained from an 18 hour nutrient agar slope culture. After 30 minutes of incubation on a rotary roller at room temperature any non-adherent bacteria were removed by washing over a $5 \mu \mathrm{m}$ membrane filter with phosphate buffered saline containing $1 \%$ D-mannose. An impression smear to a clean glass slide was then air dried, fixed in methanol for two minutes, and stained by the Gram method. An adhesion index was derived using light microscopy by counting the percentage of BECs with greater than 50 adherent Gram negative rods and subtracting from this the count obtained for the BEC source control without added bacteria. The same source of BECs was used in all assays.

The Wilcoxon rank sum test was used to assess the significance of differences in BEC adhesion indices between groups, and the $\chi^{2}$ test (with Yates' correction) was used to determine the significance of difference in numbers of isolates that were HeLa cell adhesion positive or negative for each group.

\section{Results}

Both methods showed a significant difference between colitic and control $E$ coli based on their adhesive property (figure, table). The BEC adhesion assay showed that colitic $E$ coli (median adhesion index, $44 \%$ ) were significantly more adhesive than control $E$ coli (median adhesion index $=3 \% ; \mathrm{p}<0.0002$ ), and the $\mathrm{HeLa}$ cell adhesion assay showed that a significant number of colitic $E$ coli were HeLa cell adhesion positive (13 of 25) compared with control $E$ coli $(0 / 13 ; \mathrm{p}<0.01)$. All HeLa cell positive strains were BEC adhesive (BEC index $>25 \%$ ) but eight BEC adhesive $E$ coli were HeLa cell negative. No control $E$ coli were HeLa cell or BEC positive.

\section{Discussion}

Although the HeLa cell assay is used to study bacterial adhesion, it has several theoretical disadvantages in studying gut flora. HeLa cells are derived from a

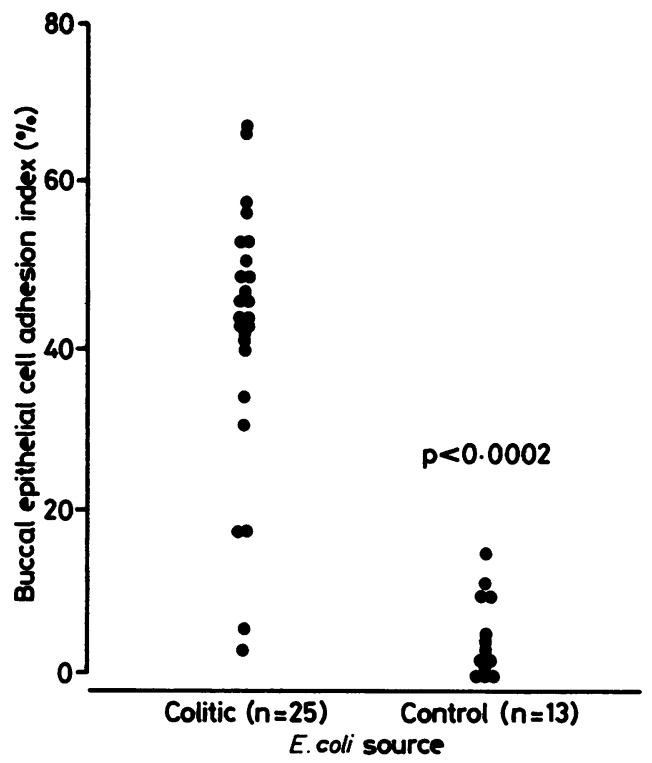

Figure $B E C$ adhesion indices of $\mathrm{E}$ coli isolates from patients with ulcerative colitis and from controls.

neoplastic cell line originally isolated from a nongastrointestinal tract source; bacterial adhesion to them may not represent the mechanisms that exist in vivo. For this reason buccal cells which have a closer association with the gastrointestinal tract may be more suitable to study. BECs may express receptors similar to those in the intestine, as enterotoxigenic $E$ coli can be cultured from the oropharynx of children during the course of infection with these pathogens. ${ }^{3}$ Furthermore, an adhesive $E$ coli has been shown to have a similar degree of adhesion for BECs and fetal enterocytes. ${ }^{4}$ These data suggest that BECs may be particularly suitable for use in the study of $E$ coli thought to have properties of intestinal adhesion.

The results of this investigation show that if both methods measure the same adhesive property then the HeLa cell assay is considerably less sensitive than the BEC assay, with $32 \%$ of BEC epithelial cell adhesion positive strains missed. This observation suggests that the previously reported incidence of $E$ coli with adhesive properties in patients with ulcerative colitis is an underestimate. ${ }^{1}$ In the present study type 1 pilus adhesion was minimised by the inclusion of $D$ -

Table HeLa cell adhesion of colitic and control E coli isolates

\begin{tabular}{llc}
\hline & E coli & \\
\cline { 2 - 3 } HeLa cell adhesion & $\begin{array}{l}\text { Patients with } \\
\text { ulcerative colitis }\end{array}$ & Controls \\
\hline Positive & 13 & 0 \\
Negative & 12 & 13 \\
\hline
\end{tabular}


mannose in the assay and by growing the organisms on solid media; type 1 pili are best expressed when grown in liquid media. ${ }^{5}$ This modification of the technique increases the importance of adhesion positive strains as it indicates mannose resistant adhesive mechanisms reminiscent of pathogenic $E$ coli.

The HeLa cell assay is more difficult to perform than the BEC assay because special care is necessary in handling cells to ensure sterility and viability of the cell line. The assessment of adhesion as used by previous workers and followed here is highly subjective and only achieves a positive or negative result. The assessment of adhesion using the BEC assay is quantitative, it is also easy to perform, and offers a simple means of screening for adhesive $E$ coli. Apart from these advantages the cells are readily accessible and the assay allows the influence of host factors to be studied by using BECs from different donors.

Using this adhesion assay previous workers chose an adhesion index of $>25 \%$ to differentiate adhesive from non-adhesive strains. ${ }^{4}$ If this criterion is applied to our results, $87.5 \%$ of colitic $E$ coli possessed a mannose resistant adhesive property.

The BEC adhesion indices of our control $E$ coli isolates compare with those found by other workers for recognised non-adhesive controls using adult BECs. ${ }^{6}$ In a previous study in our laboratory the adhesion indices of control non-adhesive $E$ coli isolates were once again similar and the BEC assay clearly distinguished between adhesive and nonadhesive standards. ${ }^{2}$ This indicates that the BEC assay can detect the differences in the adhesive ability of $E$ coli. While the cut off point of $25 \%$ is arbitrary, no control isolate had an adhesion index greater than this and the value lay more than three standard deviations from the median BEC adhesion index of the control isolates.

This study suggests that the HeLa cell assay underestimates the true incidence of $E$ coli with adhesive properties in patients with ulcerative colitis and suggests that the BEC technique is more sensitive. The observation that such a large proportion of colitic patients carry adhesive $E$ coli may have important implications in the pathogenesis and possibly the treatment of this enigmatic disease.

\section{References}

1 Dickinson RJ, Varian SA, Axon ATR, Cooke EM. Increased incidence of faecal coliforms with in vitro adhesive and invasive properties in patients with ulcerative colitis. Gut 1980;21: 787-92.

2 Burke DA, Axon ATR. Ulcerative colitis and E coli with adhesive properties. J Clin Pathol 1987;40:782-6.

3 Challacombe DN, Richardson JM, Rowe B, Anderson CM. Bacterial microflora of the upper gastrointestinal tract in infants with protracted diarrhoea. Arch Dis Child 1974;49:270-7.

4 Candy DCA, Leung TSM, Phillips AD, Harries JT, Marshall WC. Models for studying the adhesion of enterobacteria to the mucosa of the human intestinal tract. In: Elliot K, O'Connor $\mathrm{M}$, Whelan J, eds. Adhesion and microorganism pathogenicity. Tunbridge Wells: Pittman Medical, 1981:72-93.

5 Duguid JP, Clegg S, Wilson MI. The fimbrial and non-fimbrial haemaglutinins of Escherichia coli. J Med Microbiol 1979 12:213-27.

6 Candy DCA, Leung TSM, Marshall WC, Harries JT. Increase adhesion of Escherichia coli to mucosal cells from infants wittō protracted diarrhoea: a possible factor in the pathogenesis of bacterial overgrowth and diarrhoea. Gut 1983:24:538-41.

Requests for reprints to: Dr DA Burke, Gastroenterology Unit, The General Infirmary, Leeds LS1 3EX, England. 